\title{
Design and Manufacturing of Small Scale Tsunami Simulator Channel
}

\author{
Hiba A. Bachay ${ }^{1, a^{*}}$, Asad H. Aldefae ${ }^{1, b}$, Salah L. Zubaidi ${ }^{1, \mathrm{c}}$ Wissam H. Humaish ${ }^{2, \mathrm{~d}}$ \\ and Evgeny K. Sinichenko,e, \\ ${ }^{1}$ Wasit University, College of Engineering, Civil Engineering Department, Wasit, Iraq \\ ${ }^{2}$ Hydraulic and Engineering Hydrology, Peoples' Friendship University (RUDN), Russia. \\ ahibab301@uowasit.edu.iq, ${ }^{\text {b.* }}{ }^{2}$ asadaldefae@uowasit.edu.iq, ${ }^{\mathrm{c}}$ salahlafta@uowasit.edu.iq. \\ dwhumaish@,uowasit.edu.iq, ${ }^{\mathrm{e}}$ csinichenko-ek@rudn.ru
}

\begin{abstract}
Increasing the cost of in-situ or field tests to solve engineering problems, particularly water engineering, pushes researchers worldwide to simulate different water engineering problems using small-scale physical modeling like soil erosion, hydraulic jump, water flow, and underground water. This paper focuses on the design, manufacturing, and calibration of the $6 \mathrm{~m}$ small-scale tsunami simulator channel to investigate the tsunami wave behavior with time until it reaches the shore or beach. The new wave generator capable of recreating scaled tidal waves, the physical modeling of tsunamis in the laboratory, and has advanced significantly. The working principles behind the new wave generator and its design, manufacturing, and first stages of testing to validate its capacities and limitations are discussed in this paper. Each part of the generator has been represented; model preparation and new wave generator calibration have been discussed. Well, agreement of the wave height is noticed $(14 \mathrm{~cm})$, and this is replicated that the new wave simulator can reproduce solitary waves with high steepness.
\end{abstract}

Keywords: Tsunami; solitary wave; scaling law; sand; physical modeling.

\section{Introduction}

The complexity of scaling the very long and solitary tsunami wave's movement in laboratory tests has a big challenge because they generate a much steeper wave. Therefore, principles of physical modeling to design this device were followed to generate waves of lengths and heights similar to coastal waves after subjecting them to physical scaling. Experimental studies of quasi-tsunamis have been carried out using solitary waves, long waves produced by different types of wavemakers [1-3]. Solitary waves have been used as an estimated waveform for tsunami representation in many hydraulic studies [2]. A new type of tsunami generating device has been developed on a large scale commensurate with seismic events and the resulting long waves [1]. Researchers produced a new tsunami simulator machine (pneumatic tsunami generator), which consists of an inverted tank submerged at the bottom of the tank with a pump that discharges air at the top of the tank, pulling water from the channel stream into the tank. Air pump valve control gives the wave the desired shape. This type of device is ideal for generating tsunamis [1].

Experimental work was performed to study the relationship between an onshore building and a tsunami surge [4]. The study was carried out on one of the hydraulic laboratories, which consists of a tsunami simulator with $10 \mathrm{~m}$ long test channel, 2.1 meters wide, and 1.5 meters deep. The water tank is cylindrical in diameter of 3 meters, and the length of 3 meters contains a gate $3 \times 1$ meters at the top of the reservoir to provide and discharge water. The tank is equipped with an electric motor and a rotary gearbox that rotates the tank where the depth of water reaches the required level, and the faster the movement of the tank, the greater the wave. The correlations between the depth and velocity of the tsunami surge and the strain on the structure caused by the surge were presented. There were three defined force components in the surge-induced pressure-time histories. They are run-up, impulsive, and quasi-steady hydrodynamics. In addition, the review provides the difference between the obtained findings and the current recommendations for tsunamis. Full details of the experimental program were carried out utilizing a developed tsunami simulator [5]. The tsunami simulator is a 14.6 m-resistant stainless-steel channel with a width of $2.7 \mathrm{~m}$ and a depth of $1.4 \mathrm{~m}$. The channel is equipped 
with a hydraulic pump with a discharge capacity of $1.7 \mathrm{~m}^{3} / \mathrm{sec}$ and contains two glass windows to monitor the ripple effects on the screening models. At the end of the channel, an articulated gate capable of draining water at $25.5 \mathrm{~m}^{3}$ is generated by controlling the gate where it opens at high speed, creating a rapid flow of water trapped behind the gate, causing what is known as water breakage, which causes wave generation. The previous studies focused on severe hydrodynamic forces on structural models created by a turbulent hydraulic bore.

Using the wave tank experiment, the subjected tsunami loads on buildings were explored by [6]. The designed tsunami simulator includes a $45 \mathrm{~m}$ channel and a depth of $1.5 \mathrm{~m}$ and a width of $1 \mathrm{~m}$ tank base filled with sand that can be formed at a manageable angle of a mile, and the wave is generated by sudden water displacement by dropping a rectangular mass weighing about $100 \mathrm{~kg}$. The sudden water movement at the tank's deepest end is able to produce a wave that, as the structure of interest in the experiment, increased to the coast where the studied models were located. Test results showed that $5.1 \mathrm{kPa}$ was the maximum pressure at the front wall of the house that represents 127.5 $\mathrm{kPa}$ due to scaling of Froude number $(5.1 \times 25)$ for an actual house with $5 \mathrm{~ms}-1$ tsunami wave velocity. Physical modeling is, meanwhile, mostly favored by previous scientists. The physical modeling offers an obvious judgment about the effects of the waves on the defined construction as the model was built inside a lab, and the required tsunami waves were generated using a wavemaker of a wave tank. Nevertheless, concerns are raised about the accuracy of the processing of physical modeling if it creates the actual tsunami phenomenon or not. As many other conditions and parameters cannot be taken into account during the tests, they involve the friction, the topography of the area, and Manning roughness coefficient (parameter represents the resistance of surface bed channel to flow). In addition, when the waves inundate the coastal area, the produced wave velocity during the directed test may not represent the real tough velocity that hits the structures.

This paper focuses on design, manufacturing, and calibration of small-scale tsunami simulator channel in the water engineering laboratories at the University of Wasit, Iraq to investigate the tsunami wave behavior with time until reaches to the shore or beach. With the new wave generator capable of recreating scaled tidal waves, the physical modeling of tsunamis in the laboratory has advanced significantly. The working principles behind the new wave generator, as well as its design, manufacturing, and first stages of testing to validate its capacities and limitations, are discussed in this article

\section{Laboratory Experiment Scaling Law}

This section aims to ensure that the key forces driving the prototype wave are well reproduced in the laboratory setting. Potential scale effects that can impact experimental outcomes are also discussed. Since long waves are modeled (the ratio of depth to wavelength is less than 1/20), it is most fitting to apply Froude scaling. In the model using Froude scaling, the following section aims to test a standard prototype wave that is well reproduced and provides examples of model values for the wave height, time, flow velocity, and pressure to be expected during the experiments. At the end of this segment, the effects of the scale that will influence the experimental results are addressed.

Scaling for Long and Depressed Waves. The scale ratio $\left(\mathrm{N}_{\mathrm{x}}\right)$ is the ratio of a parameter in the model $\left(\mathrm{X}_{\mathrm{m}}\right)$ to the value of the same parameter in the prototype $\left(\mathrm{X}_{\mathrm{p}}\right)$, Eq. 1 [7].

$$
\mathrm{N}_{\mathrm{x}}=\mathrm{X}_{\mathrm{m}} / \mathrm{X}_{\mathrm{p}}
$$

The Froude number is a measure of the relative influence of inertial and gravity forces in a hydraulic flow. In this study, the Froude number is defined as shown in Eq. 2 [8].

$\mathrm{F}_{\mathrm{r}}=\mathrm{U} / \sqrt{\mathrm{gh}}$

Froude similitude between model and prototype is expressed in Eq. 3.

$\mathrm{F}_{\mathrm{m}}=\frac{\mathrm{U}_{\mathrm{m}}}{\left(\mathrm{g}_{\mathrm{m}} \mathrm{h}_{\mathrm{m}}\right)^{1 / 2}}=\frac{\mathrm{U}_{\mathrm{p}}}{\left(\mathrm{g}_{\mathrm{p}} \mathrm{h}_{\mathrm{p}}\right)^{1 / 2}}=\mathrm{F}_{\mathrm{p}}$ 
Where $g_{m}=g_{p}=g$ (not scaled), and $h_{p}=\lambda h_{m}$ (Geometric similarity). Thus, Eq. 3 is replaced by Eq. 4.

$$
\mathrm{F}_{\mathrm{m}}=\frac{\mathrm{U}_{\mathrm{m}}}{\left(\mathrm{g}_{\mathrm{m}} \mathrm{h}_{\mathrm{m}}\right)^{1 / 2}}=\frac{\mathrm{U}_{\mathrm{p}}}{\left(\mathrm{g}_{\mathrm{p}} \lambda \mathrm{h}_{\mathrm{p}}\right)^{1 / 2}}=\mathrm{F}_{\mathrm{p}}
$$

Then,

$$
\mathrm{U}_{\mathrm{p}}=\lambda^{1 / 2} \mathrm{U}_{\mathrm{m}}
$$

Scaled ratio $\lambda^{1 / 2}$ is required to upscale Froude model velocity. The effect of residual forces such as kinematic viscosity is minimal for phenomena where gravity and inertial forces are dominant. Most water phenomena, particularly free surface flows, are modeled after Froude (hydraulic structures, waves, wave energy converters etc.). Three criteria include mechanical similarity [8]. (i) Geometric similarity or shape similarity (i.e., all dimensions of the model's length are one times smaller than their real-world prototype $\left(1=\mathrm{L}_{\mathrm{p}} / \mathrm{L}_{\mathrm{m}}\right)$; (ii) Kinematic similarity (requires geometric similarity and motion similarity between the particles of the model and the prototype and (i) Dynamic similarity (requires geometric and kinematic similarity and, in addition, requires the identically of all force ratios in both systems.

Design of the Tsunami Simulator Apparatus. The experimental work involves the design and manufactures pneumatic wave generator channel. The main structure of the simulator device consists of a $6 \mathrm{~m}$ steel frame, sealed tank, pump, a control valve, and Plexiglas windows with dimensions of 0.8 depth and $0.8 \mathrm{~m}$ width. A pneumatic wave generator capable of producing long waves and drawing down waves is the inspiration for the current wave simulator. The tsunami simulator draws a controlled volume of water from a wave basin into a tank to accomplish this and releases it over time. Constant suction is provided by an air pump connected to the tank, and a separate motoroperated valve controls the air pressure inside the tank. It also needs a new pump to produce waves, rather than a wave basin, in the channel. In addition to these changes, the concepts behind the new wave simulator are basically the same as those in 1952 [9]. The tsunami generator is operated by a motorized valve operating by varying the pressure within the tank. The air pump provides a continuous suction. Water is drawn into the tank from the channel when the control valve (CV) is closed and released back to the channel when the valve is opened. It must prevent the water level from hitting the top of the tank and being drawn into the air pump to avoid damage. The draw-up point creates the water released forms the positive part of the wave and the negative trough in the channel. The experimental setup is discussed in detail in the following sections.

Main Frame of the Simulator. Many previous researchers have designed channel models of different materials and different dimensions for use in hydraulic studies described in detail [10,11]. Figure 1 shows the mainframe of the channel used for the tsunami wave simulator mentioned in this paper. The length of the channel is 6 by 0.8 meters high and $0.8 \mathrm{~m}$ wide is made of steel plates with viewing windows of Plexiglas plates $(1$ by $1 \mathrm{~m})$. A pneumatic wave generator is mounted in front of the left side of the channel. In order to capture video data camera is installed to collect data. With freshwater, the channel is filled up to various depths for various tests. Separately, the various types of data observed are listed. Most of the data is collected using several channel data acquisition devices that allow all amounts to be reported simultaneously. In the case of sump volumes, other measurements, in particular video recording, need a separate recording device or manual measurements. After the steps mentioned above, which will be explained in detail in the next paragraphs, the boundary conditions of the channel have been tested by conducting a preliminary examination to ensure that these dimensions give a required wave. 


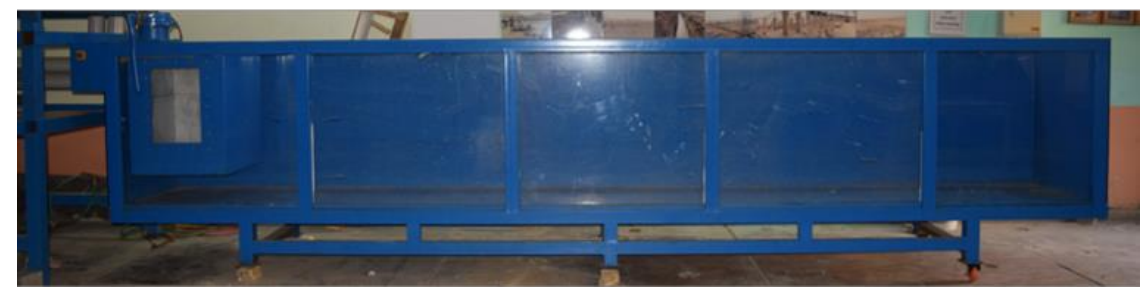

Figure 1. The mainframe of the Tsunami simulator Apparatus.

The Inverted Water Storage Tank. Water tank, which is $0.8 \times 0.6 \times 0.6 \mathrm{~m}$, is installed upside down at the beginning of the channel so that the hole at the bottom of the tank is submerged in the water of the channel where the tank works to pull the water mass from the channel by emptying the air and can control the amount of water drawn by the buttons on the control panel (Figure 2a).

The Water Pump. The high-pressure air pump pulls air from the tank, reducing pressure and pulling water from the canal up to the tsunami simulation tank (this simulates the process of retreating seawater before the tsunami and following the process of rushing water to the coast), where the two valves control it and release the amount of water drawn into the reservoir (Figure 2b)

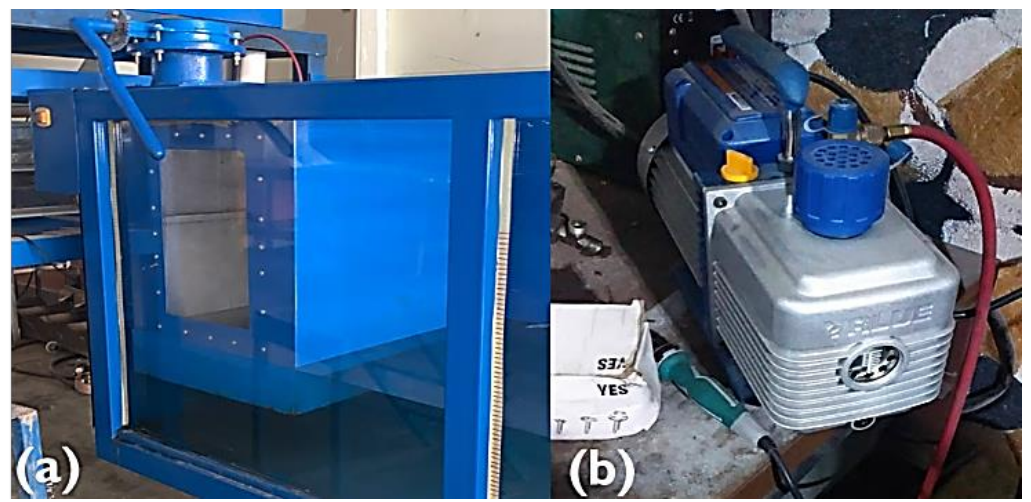

Figure 2. (a) Sealed water tank and (b) the pump.

The Control Valves. Two control valves are provided to control the process of water withdrawal and decompression to ensure the tightness of the tank lock and do not leak air into the tank, which leads to the complete discharge of air from the tank and raise the water mass to the top of the tank and when the valve is opened very quickly through the conjunctivitis arm the waterfalls freely, leading to the filling of the tsunami waves (Figure $3 \mathrm{a}$ and $\mathrm{b}$ ).

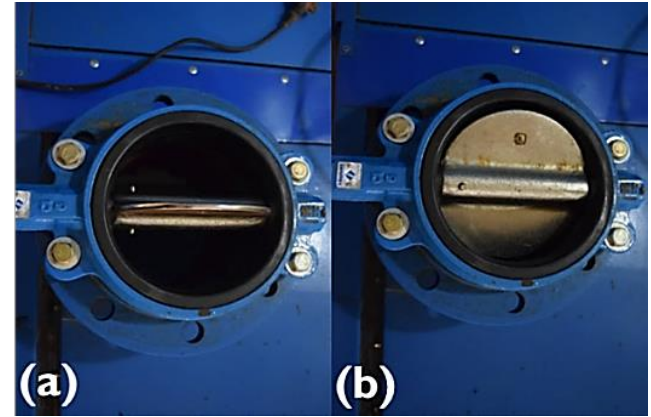

Figure 3. Control valves

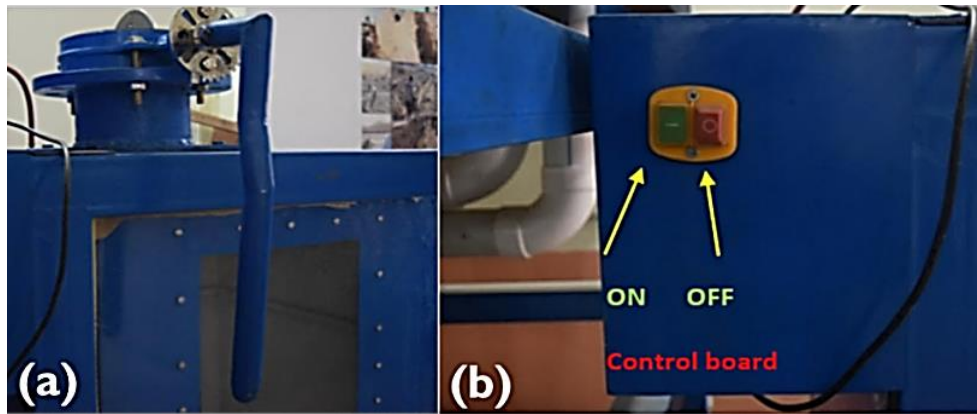

Figure 4. (a) The mechanical control arm and (b) The electrical control board.

The Mechanical Control Arm and Electrical Control Board. Through the control arm, the valve can be sealed or opened by moving it up and down. Whereas the control panel contains a set of buttons through which control, switching on and off. The electrical circuit responsible for the operation of the device. Figure 4 shows the mechanical arm and the electrical board. 


\section{Verification of the Designed Tsunami Channel}

To calibrate the tsunami simulator channel, model preparation simulates the actual shore model (beach) as seen in the prototype scale. This requires soil that has properties close to the soil properties at the oceans and seas coasts which was the silica sand (passed on \#10 sieve). The sandy soil (silica sand) is very close to this kind of soil [13], and the soil in the prototype scale (i.e., the shore of seas) is mixed with different types of soil, and the sand is the largest soil-forming that places. Basically, the fine-grain soil (i.e., the sand here) should not be scaled downed in the model scale as described before [12].

The Soil Bed Preparation. The bed soil of the model in the channel is prepared according to the sand raining technique (i.e., air pluviation) in which the sand particles fall down the model from the appropriate height, and desire opening slot ranges between 2 to $7 \mathrm{~mm}$. This technique is used commonly in the different models' preparations [14,15]. The sand density in the laboratory is calibrated before using the wave channel itself. The sand was placed within the template in several layers using pluviator device that was designed and manufactured by [16]. A dense state specimen is prepared at $68 \%$ relative density. After that, the channel was filled with water for four days to allow for sand to be consolidated and saturated with water. This procedure allows the soil to be at a similar in-situ condition as the coasts and shores are dandified under the phenomenon of the tides. The soil used as the basis of the physical model is golden yellow silica sand. The sand was used because of the difficulties and limitations associated with the simulation of rocky soils (i.e., size requirements) as well as the preparation difficulties in the channel device. The properties of the sand used in this analysis are cohesionless soil, which is very similar to the properties of HST95 silica sand, which is widely used by researchers in numerous laboratories around the world $[15,16]$.

The sand was first cured in an oven for 24 hours. The substance was then sieved on \#10 to eliminate the larger particles. In the laboratory, the key physical properties were described to equate them to those of HST95 silica sand, which is commonly used [17-19]. The maximum and minimum densities were estimated using ASTM D4254 and D4253, respectively, and the specific gravity, $\mathrm{G}_{\mathrm{s}}$, was determined using ASTM D854-14 [20]. The USCS was used to identify the prepared sand. It was clayey sand with a poor grade (i.e., SP-SC). The particle size distribution, PSD, for the prepared sand is shown in Figure 5. The figure indicates that the sand particle size is identical to HST95 silica, widely used in geotechnical physical simulation research centers and studies [21,22]. The key physical properties of the sand used and the properties of both HST95 silica sand are shown in Table 3. Using these sand properties in physical modeling is to be compatible with what others around the world are doing.

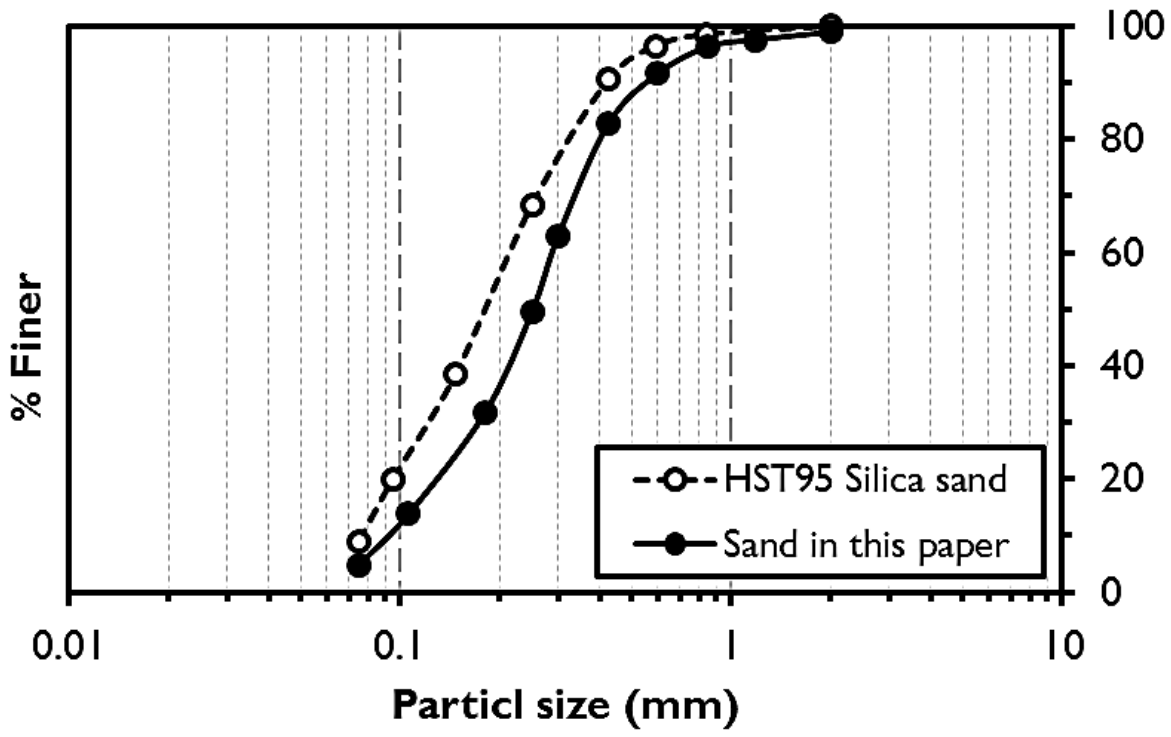

Figure 5. PSD of silica sand used in the model preparation. 
Table 1. Physical properties of used sand.

\begin{tabular}{|l|c|c|c|}
\hline \multicolumn{1}{|c|}{ The property } & Sand & HST95 Silica sand & Ottawa sand \\
\hline Specific gravity, $\mathrm{G}_{\mathrm{S}}$ & 2.67 & 2.63 & 2.64 \\
\hline Shape & Rounded & Rounded & Rounded \\
\hline Mean particle size, $\mathrm{D}_{\mathrm{S}}$ & 0.28 & 0.15 & 0.32 \\
\hline Coefficient of uniformity, $\mathrm{C}_{\mathrm{u}}$ & 2.85 & 1.9 & 1.68 \\
\hline Coefficient of gradation, $\mathrm{C}_{\mathrm{z}}$ & 1.32 & 0.95 & 1.08 \\
\hline Minimum dry unit weight, $\gamma_{\operatorname{dmin}}\left(\mathrm{kN} / \mathrm{m}^{3}\right)$ & 14.8 & 14.7 & 14.9 \\
\hline Maximum dry unit weight, $\gamma_{\mathrm{dmax}}\left(\mathrm{kN} / \mathrm{m}^{3}\right)$ & 19.1 & 19.2 & 19.5 \\
\hline
\end{tabular}

The Shore Profile. The shore profile reflects the difference in elevation (or depth) as a function of distance offshore and is the "shape" of the beach. The height generally declines (depth increases) with distance farther inland, for example. In general, a natural coast or beach profile is determined over a transect perpendicular to the shoreline and from the dune to an offshore position where the altitude varies less over time (called closure depth). The beach slope calculates the steepness of the beach profile (rise/run) that can be specified between any two points on the beach profile. The beach slope along the shoreline is mainly controlled by run-up and rundown swash zone processes and is correlated to the grain scale. Beach slopes with greater grain sizes tend to be steeper, and this helps to regulate the breaking wave by shoaling wave variations [23]. Sand shore model was prepared, and beach profile model is simulated as much as possible. Several beaches along the U.S. Pacific Coast (Figure 6) as well as several other beaches, are determined as proposed [24]. Based on the natural beach profiles in this experiment, 1:10 beach slope was used.

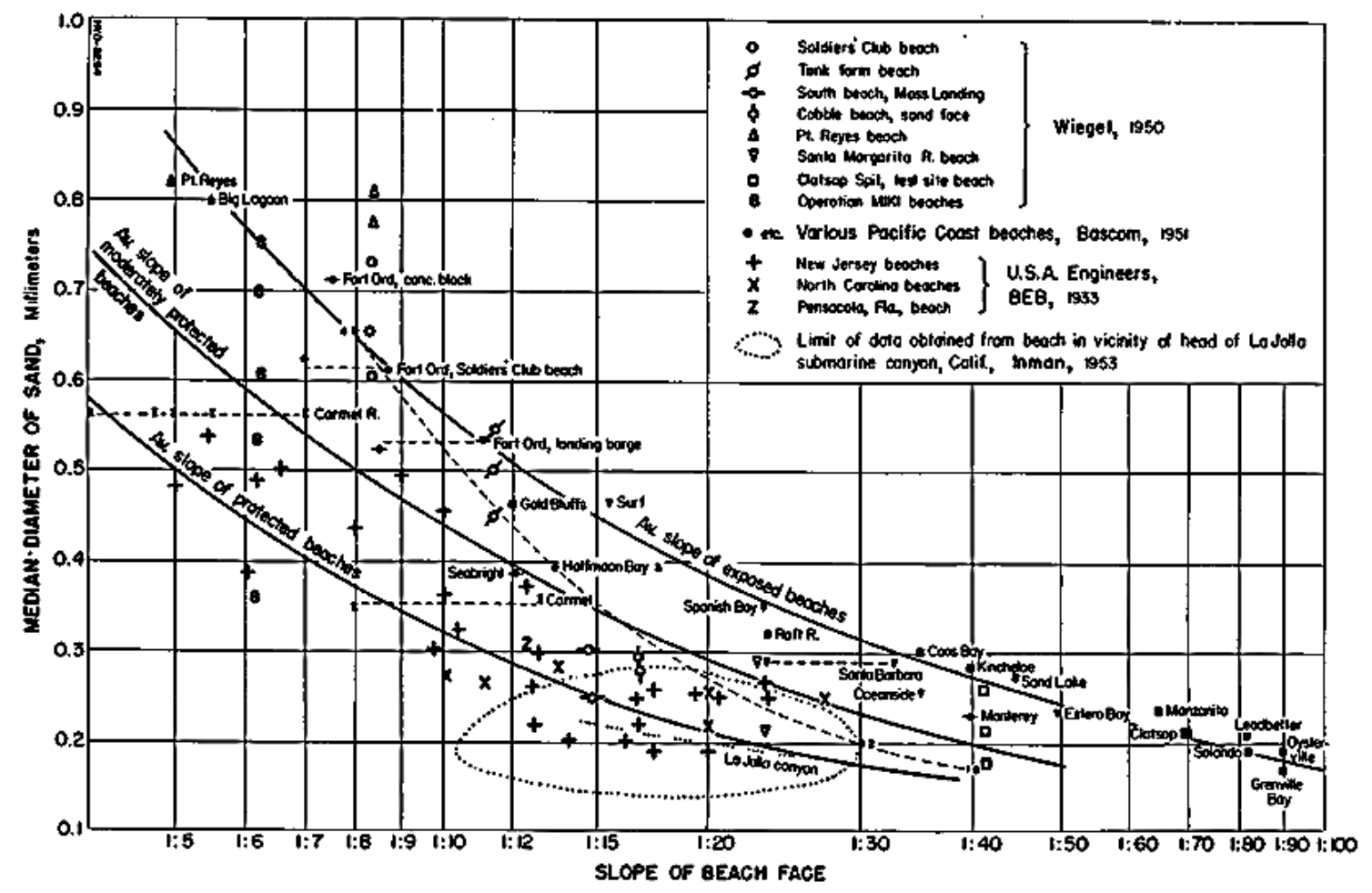

Figure 6. Size-slope relationship of beaches at the reference point [24].

As shown in Figure 7, three successive pictures representing the physical model preparation starting from the bed soil preparation, shore model preparation, and then filling the channel. 


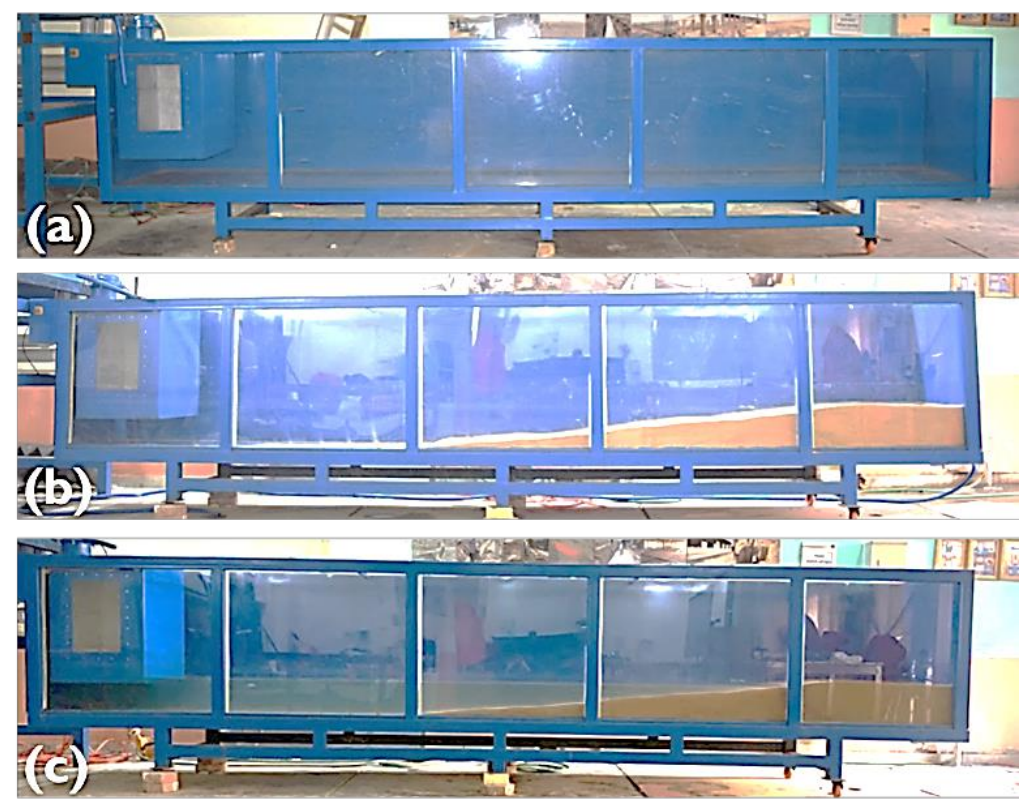

Figure 7. Physical model preparation.

The Dummy Structure Model. A dummy model building is designed to test the wave/flow forces on structures. This building is fitted with instruments for force recording, such as pressure transducers. The construction of structural materials and dimensions are very different all over the world. However, the aim here is not to replicate a particular case scenario on a model scale but to obtain general information on long waves interacting with structures of different locations. To construct the model buildings used in the experiment, general building dimensions are deduced and scaled to 1:100. The two pressure transducers are inserted through a threaded hole on the inside of the case such that they are flush with the outer surface (Figure 8a). The entire structure is bolted to a hardwood base. On dry ground, the base is flush with sandy bathymetry. Waterproof transducer cables were run from the back of the flume to the data logger system. The linear variable differential transformer (LVDT) is a type of electrical transformer connected to the model structure to record horizontal motions, as shown in Figure 8c. It is clearly shown in Fig. 8 that both kinds of sensors (i.e. water pressure and displacement transducers) were attached to a data logger device (LabJack T7PRO) that transmitted the electronic signal from the model to the computer.
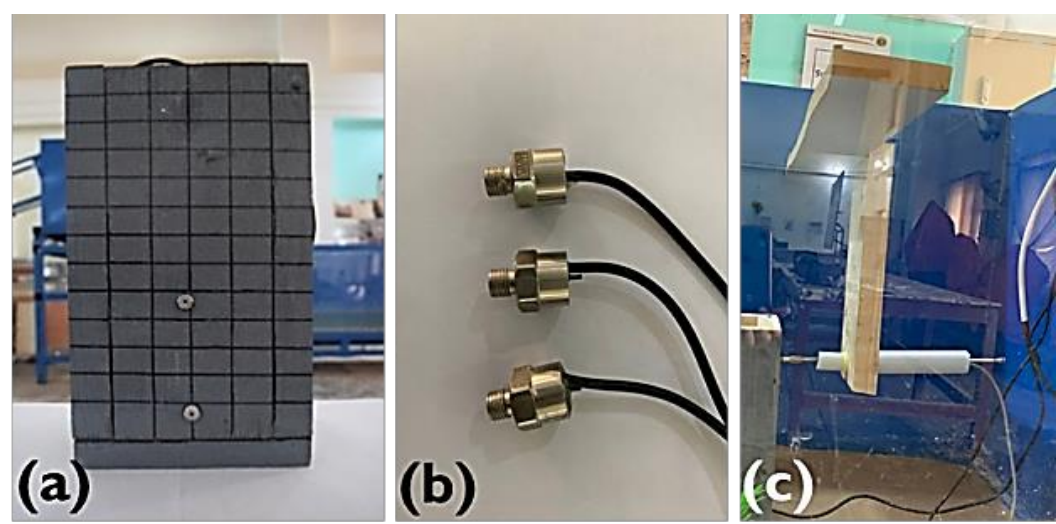

Figure 8. The (a) dummy structure; (b) The water pressure sensors, and (c) LVDT.

The computer collects the sensor readings (voltages) using Labview software. Global Instruments' Labview (Laboratory Virtual Instrumentation Engineering Workbench) interface and development environment with a visual programming language. The Labiew interactive vocabulary is a novel approach to designing calculation and control applications for scientists and engineers. It's also known as a data collection and instrument management platform that's simple to pick up and use. 

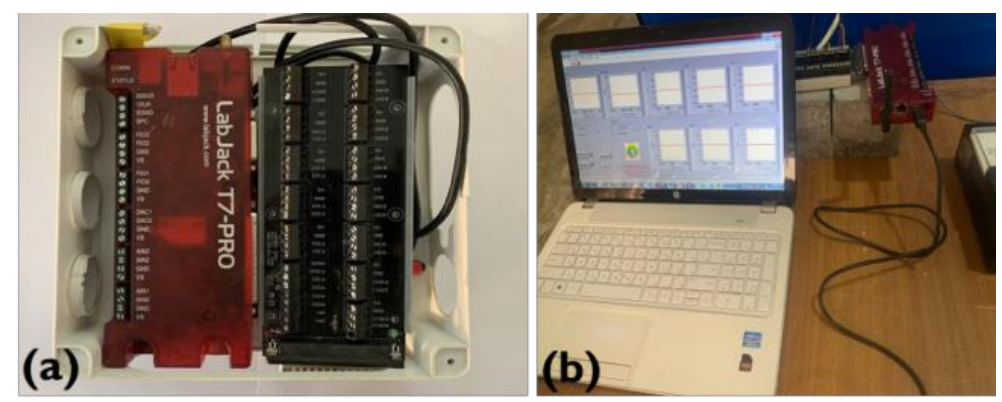

Figure 9. Data collecting; (a) Lab jack T-7 Pro data logger and (b) LabVIEW software.

Calibration of the Tsunami Wave. One of the main variables to consider when regulating the device is the depth of water in the channel, the amount of water inside the tank, and the speed and height of the wave. The water depth in the channel is subject to limits that generate waves in shallow water, which is the following limitation [25] (Eq. 6):

$\mathrm{h} / \mathrm{L}<0.05$

Where $\mathrm{h}$ is the water depth and $\mathrm{L}$ is the wavelength. The wave can be calculated from the shallow water wave speed equation (Eq. 7):

$\mathrm{c}=\sqrt{\mathrm{gh}}$

Where $\mathrm{c}$ is the wave celerity, and $\mathrm{g}$ is the gravitational acceleration.

The channel is designed based on the n-wave similar in the form of the tsunami, and the design method is summarized in the following steps: (i) When the worst cases are considered when the wave, which causes a tsunami to appear as a water wall and is very walled, shallow water equation parameters dictate that the wave height ratio should not exceed 0.75 from the depth of the water as shown in Eq. 8 [26].

$\mathrm{H} \geq 0.75 \mathrm{~h}$

Figure 10 shows the theoretical parameters of the tsunami wave.

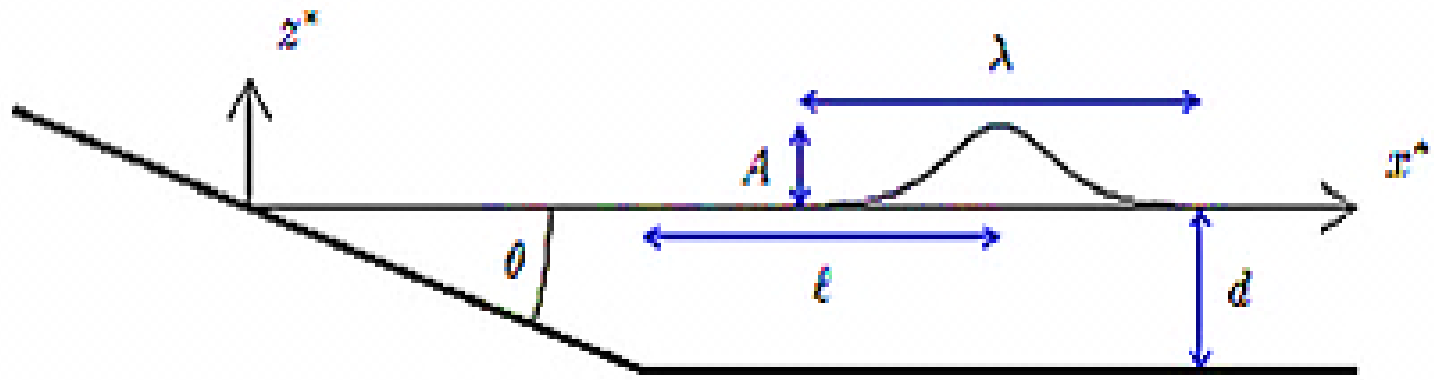

Figure 10. Theoretically explains the transactions of wave details [14].

The following equation (Eq. 9) was followed to design a single long wave model with a scale of $1 / 100[22]$.

$l=-\ln 0.00025 \mathrm{~d} / \sqrt{3 \mathrm{~A} / \mathrm{d}}$

Where 1 is the minimum propagation length, $d$ is the water depth $(\mathrm{h})$, and $\mathrm{A}$ is the wave amplitude.

For example, using a water depth of $30 \mathrm{~cm}$, the wave height theoretically should be (the lowest wave height required) of $22 \mathrm{~cm}$ with a symmetry of $11 \mathrm{~cm}(\mathrm{~A}+)$ above the water surface and $11 \mathrm{~cm}$ underwater $\left(\mathrm{A}^{-}\right)$. The a-wave capacity is the upper part above the water surface. In the experimental work, the positive amplitude is considered because of using solitary wave in simulation. By applying the equation above, the length needed to generate the wave must be approximately $2.5 \mathrm{~m}$ and is subject to change by changing the depth of the water in the channel. While the beach region was 
designed using sand with a diameter of $0.28 \mathrm{~mm}$ and a slop 1:10 and a height of $25 \mathrm{~cm}$ coast area, the coast area will extend to $2.5 \mathrm{~m}$, which was based on the following chart, in which the slope of real beaches was determined and connected to the diameter of the grains of sand found in these areas of these beaches showed in Figure 6. At the same time, the non-submerged area was estimated at $1 \mathrm{~m}$. Therefore, the total length of the channel will include the propagation length $(2.5 \mathrm{~m})+$ the beach $(2.5$ $\mathrm{m})$ as well as the non-submerged beach $(1 \mathrm{~m})$. Thus, the total length of the channel will be $6 \mathrm{~m}$. When the test was performed after completing the physical model, the wave of the device was obtained as shown from the successive pictures in Figure 11.
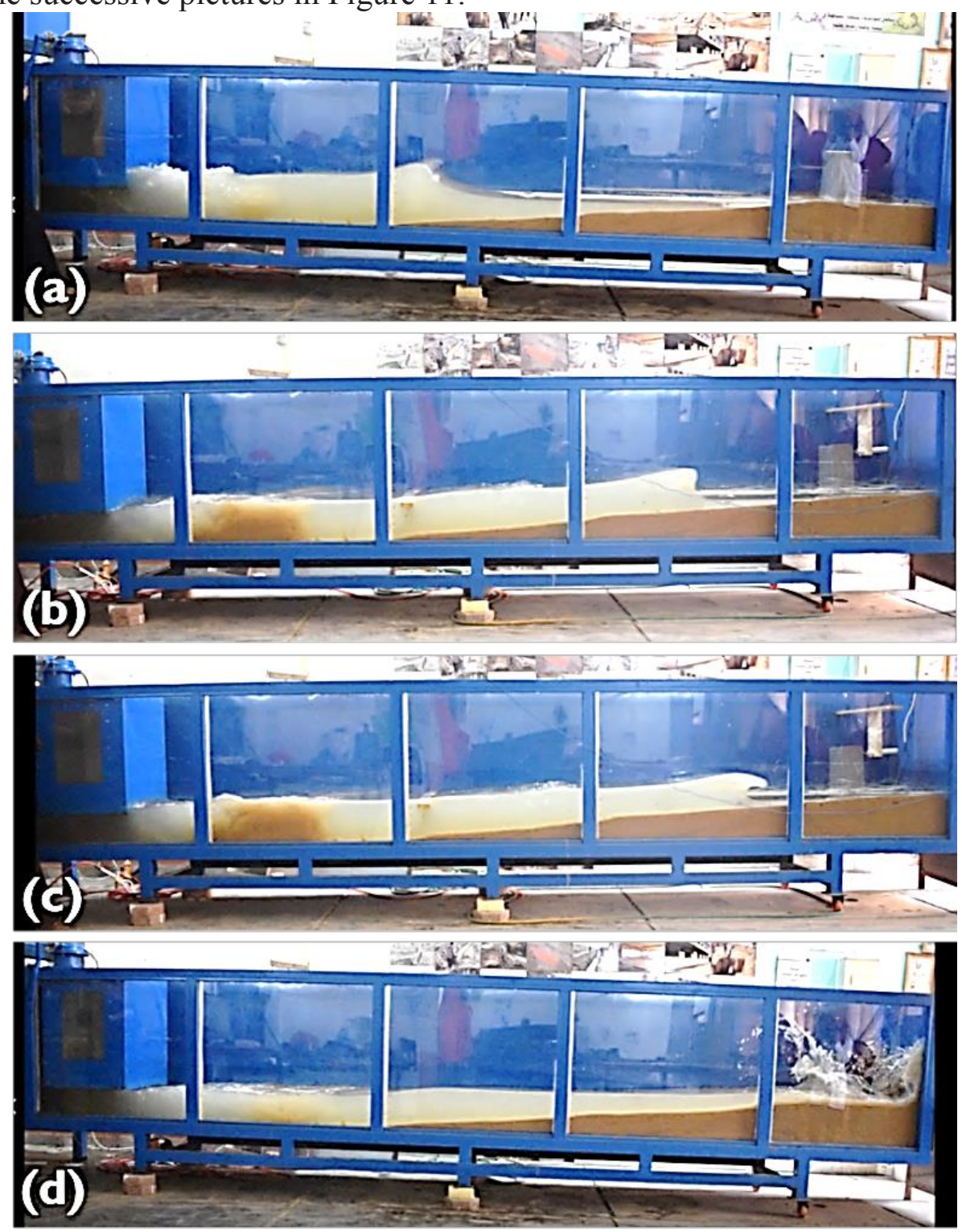

Figure 11. Calibration of tsunami simulator machine (a) The wave kickoff; (b) Wave propagation; (c) Wave hits the shore and (d) Wave structure-interaction.

In the calibration tests, a high-speed camera was used to record the movement of the tsunami wave. Three seconds of video footage was taken at a frame rate of 60 frames per second, beginning right before the wave hit the model structure. Per 10 frames, clips were extracted from the video footage, resulting in a time gap of 0.16 seconds between each clip. Wave height measured Using Origin Pro 2019 software [27] for image analysis where each one $\mathrm{cm}$ is 37 pixels, so the wave elevation at the start of the wave will be $7.6 \mathrm{~cm}$. From the measured data and using the image processing technique, a wave of $14 \mathrm{~cm}$ above the static water surface closes the shore was obtained (Figure 12) with a net water depth of $22 \mathrm{~cm}$, and this finding simulated the real tsunami wave in the prototype scale, and it was very close to what has been inspected by $[3,6]$. 


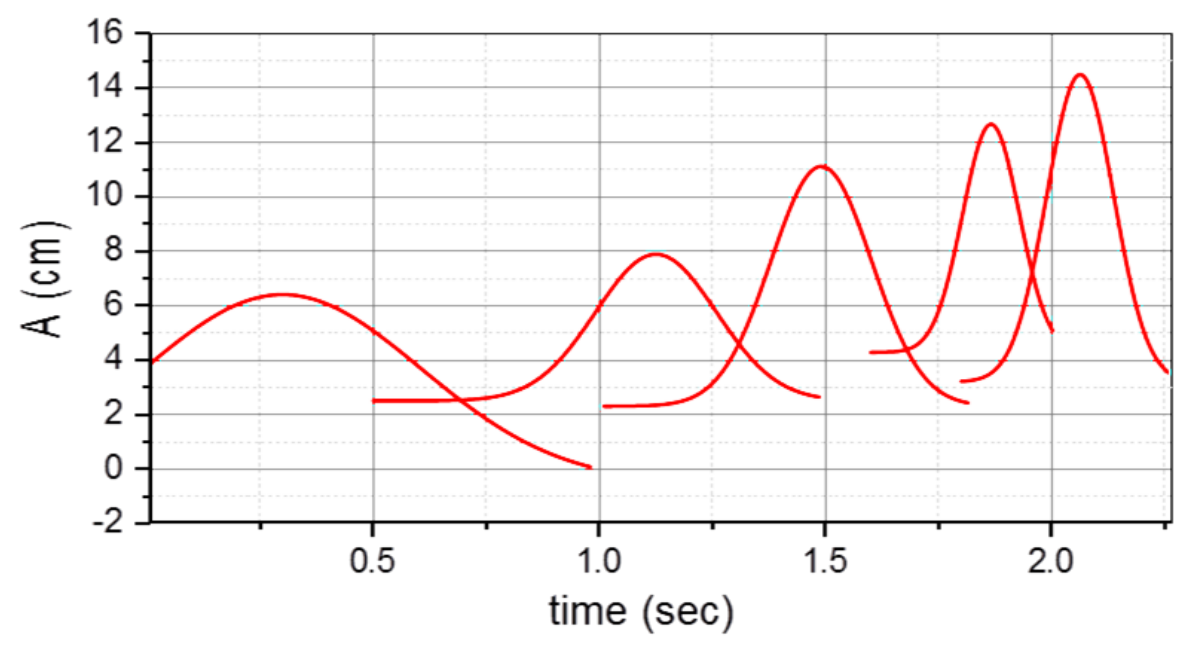

Figure 12. Amplitude increases with time.

\section{Conclusions}

Principles of physical modeling are conducted to design, manufacture, and calibrate small-scale tsunami simulator machines to understand the movement mechanism of the tsunami wave. Several factors contribute to the destabilization of the wave, including wavelength, wave height, and geometric factors of the shore or the beach (i.e., slope). The following conclusions can be summarized:

- The paper focuses on using a new facility built to simulate a nearshore tsunami at $1 / 100$ scale in a designed solidarity wave channel (Froude scaling).

- Each part of the pneumatic wave generator was described and discussed, and The concepts of physical modeling were used to prepare the beach model by using sand with slop similar to the natural beaches.

- Through testing, it has been shown that the tsunami generator can generate a solitary wave with high steep at small water depths, which represent the behaver of shallow-water waves. 12 $\mathrm{cm}$ of wave height is obtained for $23 \mathrm{~cm}$ water depth in the channel.

- The calibration of the tsunami simulator channel using a small-scale shore model and the obtained results using the designed device showed good agreement with the actual comment waves at the prototype scale. Most developed waves occur close to the shore having height more than the waves when they were far from the shore or the beach.

\section{References}

[1] Madsen, P.A., Fuhrman, D.R. and Schäffer, H.A., 2008. On the solitary wave paradigm for tsunamis. Journal of Geophysical Research: Oceans, 113(C12).

[2] Mokhtar, Z.A.B., 2019. Modelling tsunami bore-induced pressures on various seawall types. Ph.D. Thesis, Universiti Putra Malaysia.

[3] Rossetto, T., Allsop, W., Charvet, I. and Robinson, D.I., 2011. Physical modelling of tsunami using a new pneumatic wave generator. Coastal Engineering, 58(6), pp.517-527.

[4] Farahmandpour, O., Marsono, A.K., Forouzani, P., Md. Tap, M. and Abu Bakar, S., 2020. Experimental simulation of tsunami surge and its interaction with coastal structure. International Journal of Protective Structures, 11(2), pp.258-280.

[5] Stolle, J., Goseberg, N., Nistor, I. and Petriu, E., 2019. Debris impact forces on flexible structures in extreme hydrodynamic conditions. Journal of Fluids and Structures, 84, pp.391-407.

[6] Thusyanthan, N.I. and Gopal Madabhushi, S.P., 2008, May. Tsunami wave loading on coastal houses: a model approach. In Proceedings of the institution of civil engineers-civil engineering (Vol. 161, No. 2, pp. 77-86). Thomas Telford Ltd. 
[7] Briggs, M.J., 2013. Basics of physical modeling in coastal and hydraulic engineering. ERDC/CHL CHETN-XIII-3, Vicksburg, MS: US Army Engineer Research and Development Center

[8] Heller, V., 2012. Model-prototype similarity. 4th Coastlab Teaching School, Wave and Tidal Energy, (January), pp.17-20.

[9] Wood, D.M., 2003. Geotechnical modelling (Vol. 1). CRC press.

[8] Wilkie, M.J. and Young, G.A.J., 1952. Pneumatic tide generator. The engineer, 25, pp.133-137.

[11] Aldefae, A.H., Shamkhi, M.S. and Khalaf, T., 2019. Design and manufacturing of geotechnical laboratory tools used in physical modeling. Cogent Engineering, 6(1), p.1637622.

[12] Aldefae, A.H., Alkhafaji, R.A., Shamkhi, M.S. and Kumer, H.Q., 2019. Design and manufacturing of flume apparatus to investigate the failure mechanism of riverbanks. Cogent Engineering, 6(1), p.1655234.

[13] Al-Aayedi, H.K., Aldefae, A.H. and Shamkhi, M.S., 2020, June. Seismic performance of bridge piers. In IOP Conference Series: Materials Science and Engineering (Vol. 870, No. 1, p. 012069). IOP Publishing.

[14] Aldelfee, A.N. and Aldefae, A.H., 2021, February. Seismic performance of gravity quay wall. In IOP Conference Series: Materials Science and Engineering (Vol. 1058, No. 1, p. 012033). IOP Publishing.

[15] Alaayedi, H.K., Aldefae, A.H., Shamkhi, M.S. and Humaish, W.H., 2021, February. Dynamic response of different bridge piers. In IOP Conference Series: Materials Science and Engineering (Vol. 1058, No. 1, p. 012045). IOP Publishing.

[16] Aldefae, A.H. and Saleem, H.D., 2020, June. Design, Manufacturing and Testing of Biaxial Mechanical Travelling Pluviator. In IOP Conference Series: Materials Science and Engineering (Vol. 870, No. 1, p. 012071). IOP Publishing.

[17] Aldefae, A.H. and Alkhafaji, R.A., 2021. Experimental and numerical modeling to investigate the riverbank's stability. SN Applied Sciences, 3(2), pp.1-16.

[18] Al-Defae, A.H., Caucis, K. and Knappett, J.A., 2013. Aftershocks and the whole-life seismic performance of granular slopes. Géotechnique, 63(14), pp.1230-1244.

[19] Cerfontaine, B., Knappett, J.A., Brown, M.J. and Bradshaw, A.S., 2019. Effect of soil deformability on the failure mechanism of shallow plate or screw anchors in sand. Computers and Geotechnics, 109, pp.34-45.

[20] Annually, R.I., 1995. ASTM STANDARDS.

[21] Al-Defae, A.H. and Knappett, J.A., 2014. Centrifuge modeling of the seismic performance of pile-reinforced slopes. Journal of Geotechnical and Geoenvironmental Engineering, 140(6), p.04014014.

[22] Kumar, P.P., Patra, S. and Haldar, S., 2020. Behaviour of Screw Pile Under Axial Compressive and Lateral Loading in Sand for Offshore Energy Foundations. In Advances in Offshore Geotechnics (pp. 393-403). Springer, Singapore.

[23] Puleo, J.A., 2020, February. Making Waves in the Classroom-Engaging Students in STEM through Hands-on Coastal Oceanography and Engineering. In Ocean Sciences Meeting 2020. AGU.

[24] Bascom, W.N., 1951. The relationship between sand size and beach-face slope. Eos, Transactions American Geophysical Union, 32(6), pp.866-874.

[25] Sorensen, R.M., 2005. Basic coastal engineering (Vol. 10). Springer Science \& Business Media.

[26] Synolakis, C.E. and Bernard, E.N., 2006. Tsunami science before and beyond Boxing Day 2004. Philosophical Transactions of the Royal Society A: Mathematical, Physical and Engineering Sciences, 364(1845), pp.2231-2265.

[27] Sridhar, K. and Charles, A.L., 2019. In vitro antioxidant activity of Kyoho grape extracts in DPPH and ABTS assays: Estimation methods for EC50 using advanced statistical programs. Food Chemistry, 275, pp.41-49. 